Uta Frith, Robert Hodapp, Susan Gregory and Nick Boras.

Certainly due to the widely ranging topics Overcoming Barriers will be of interest to a multi-disciplinary readership. The psychiatrist of learning disability may be disappointed there is only one book about psychiatry and no specific book dedicated to epilepsy, forensic issues, behavioural phenotypes or psychotherapy. It is unlikely any single publisher can really provide a collection of books that is truly comprehensive or cutting edge and the future probably lies with collaboration between publishers.
From a technical point of view the 'Dyna Text' interface is fairly basic, but does incorporate hypertext, search facilities and a journal recording option which will repeat your browsing steps. Anything less than a 17" monitor and $1024 \times 768$ resolution makes viewing a bit strained and awkward. The system requirements are 386 processor or higher, Windows 3.1 or above, greater than $4 \mathrm{MB}$ of RAM, 2 speed $C D-R O M$, and $10 \mathrm{MB}$ of disk space.

In summary, this is a useful CD-ROM and should be considered as a reference resource in a library with computer facilities. The use of hypertext can make finding information easier than wandering through reference lists and indexes. However, I suspect few people will read the full 18 books on a computer screen. Personal users, unless they are particularly keen on this medium, are more likely to buy two or three of the books from the list which relate more closely to their area of interest.

Tim Andrews, Consultant in Learning Disability sychiatry, Oxford Learning Disability NHS Trust, Slade House, Horspath Driftway, Headington, Oxford OX3 7JH

\title{
miscellany
}

\section{UK Brain Injury Psychiatrists Group}

The UK Brain Injury Psychiatrists Group consists of consultant psychiatrists practising in the UK who manage beds for people with problems related to acquired brain injury. The group was convened by Dr Ken Barrett in 1997, following the publication of the Health Advisory Service report on neuropsychiatric disorders, Heading for Better Care, and first met in September 1997. Informal meetings are held twice a year at the Royal College of Psychiatrists. The present chairman of the group is Dr Simon Fleminger and the secretary is Dr Anjun Bashir. The overall aim of the group is to improve the quality of psychiatric management for people who have suffered non-progressive acquired brain injury. Specific aims are: to develop a uniform method of psychiatric assessment for people with acquired brain injury; to develop treatment guidelines for use in this group of patients; to develop training opportunities for psychiatrists in the management of psychiatric consensus of acquired brain injury; to facilitate research on the psychiatric consequences of acquired brain injury; and to create a support network for psychiatrists working in this area.

Specific areas of work undertaken by the group include the development of an acquired brain injury version of Health of the Nation Outcome Scales (HoNOS-ABI), presently being piloted in collaboration with the Royal College of Psychiatrists' Research Unit, and the development of an aide-mémoire for psychiatrists undertaking a neuropsychiatric assessment of a patient with an acquired brain injury. The group is in the early stages of developing a small common database that may be used to facilitate research in this field and is looking at evidence based guidelines for the management of psychosis following acquired brain injury. For further information or to take part in this group please write to Dr Simon Fleminger, The Maudsley Hospital, Denmark Hill, London SE5 8AZ.

\section{forthcoming events}

The National Schizophrenia Fellowship would like to announce the following conferences: Advances in Care and Treatment, which takes place in Leeds on 8 June 2000 and Caring for the Carers, which takes place in Birmingham on 22 June 2000. Further information: Emma Garoushe (telephone: 0208547 9202).

Alcohol Concern are the sponsors of a new national network for people who work with children, families and others affected by the problems of alcohol abusers. The new network will be launched at a one-day conference entitled Trouble Within? on 8 June 2000 in Leicester. Examples of best practice will be highlighted by experienced professionals. Further information: Rachel Morley or Carole Sired, Alcohol Concern (telephone: 0207928 7377).

Working with Trauma is a one-day conference and workshop being organ ised under the auspices of EMDR (UK and Ireland) Northampton and Oxford on 6 July 2000 at St Andrew's Hospital, North- ampton. Topics will include: working with burns and road traffic victims; and vicarious traumatisation - what do you do with the helpers? Further information: Mary Wild, St Andrew's Hospital, Billing Road, Northampton NN1 5DG (telephone: 01604616 630; fax: 01604616 623).

It is proposed to hold the Second

Meeting of the Royal College of Psychiatrists' Golf Society on Friday 7 July 2000, after closure of the College's Annual Meeting in Edinburgh. Places are limited to 30 golfers and transport will be provided to and from the course. Teetimes have been reserved from $2 \mathrm{pm}$ onwards. Further information: Dr A. M Stewart, Consultant Psychiatrist, Greystanes House, Royal Dundee Liff Hospital, Dundee (telephone: 01382423 109).

The Sainsbury Centre for Mental Health are the organisers of the following conferences: Interventions into Practice, being held in Harrogate on 27-28 June 2000, will focus on issues relating to implementing evidence-based interventions into routine clinical practice:
Recruitment and Retention, being held in London on 12 July 2000, will look at the problems of recruitment and retention in mental health services and analyse creative solutions. Further information about both events: The Conference Department, The Sainsbury Centre for Mental Health, 134-138 Borough High Street, London SE1 1LB (telephone: 0207827 8384; fax: 0207403 9482; web site: www.sainsburycentre.org.uk)

The Anna Freud Centre would like to announce the first international neuropsychoanalysis conference entitled

Neuroscientific and Psychoanalytic Perspectives on Emotion. The event will take place on 21-23 July 2000 at the Royal College of Surgeons, London. The aim of this meeting is to build bridges between psychoanalysis, neuroscience, cognitive science and biological psychiatry. There will be abundant time for discussion and an International Neuro-Psychoanalysis Society will be established at the meeting. Further information: The Anna Freud Centre, 21 Maresfield Gardens, London 
NW3 5SD (telephone: 0207794 2313; fax: 0207794 6506; e-mail: annafreudcentre (a) compuserve.com)

Professor R. N. Mohan, Consultant in Old Age Psychiatry and Clinical Tutor, Northern Birmingham Mental Health NHS Trust is the organiser of three two-day courses: Mental Health Law Update for Specialist Registrars in Psychiatry, being held on 12-13 October 2000,
Mental Health Law Update for NonConsultant Career Grade Doctors, being held on 26-27 October 2000 and Mental Health Law Update for Consultant Psychiatrists, taking place on 9-10 November 2000. Fur ther information about all three courses, which will be held at the Birmingham Medical Institute: Mrs Denise Makepeace (telephone: 0121685 6574).

The Society for Psychosomatic
Ophthalmology and The British PsychoAnalytical Society would like to announce a one-day symposium entitled Psyche and Sight Loss. The event will take place on 4 November 2000 at The Institute of Psycho-Analysis, London. Further information and application form: Mandy O'Keeffe, 67 Avenell Road, London N5 1BT (telephone: 0207288 2359; e-mail: okeefe@ukgateway.net). 